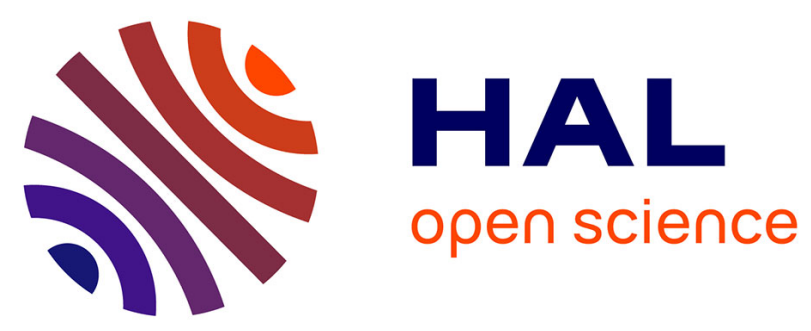

\title{
Digital Transformation Within the Emobility Market-Learnings and Insights from Early Market Development
}

\author{
Andreas Pfeiffer, Matthias Jarke
}

\section{- To cite this version:}

Andreas Pfeiffer, Matthias Jarke. Digital Transformation Within the Emobility Market-Learnings and Insights from Early Market Development. 3rd and 4th International Conference on Smart Energy Research (SmartER Europe 2016 and 2017), Feb 2016, Essen, Germany. pp.23-42, 10.1007/978-3319-66553-5_2 . hal-01691203

\section{HAL Id: hal-01691203 https://hal.inria.fr/hal-01691203}

Submitted on 23 Jan 2018

HAL is a multi-disciplinary open access archive for the deposit and dissemination of scientific research documents, whether they are published or not. The documents may come from teaching and research institutions in France or abroad, or from public or private research centers.
L'archive ouverte pluridisciplinaire HAL, est destinée au dépôt et à la diffusion de documents scientifiques de niveau recherche, publiés ou non, émanant des établissements d'enseignement et de recherche français ou étrangers, des laboratoires publics ou privés. 


\title{
Digital Transformation within the Emobility Market- Learnings and Insights from early Market Development
}

\author{
Andreas Pfeiffer ${ }^{1}$, Matthias Jarke ${ }^{1}$ \\ ${ }^{1}$ Chair of Information Systems, Ahornstr. 55, 52064 Aachen, RWTH Aachen University \\ pfeiffererwth-aachen.de, jarkeedbis.rwth-aachen.de
}

\begin{abstract}
This paper presents a generic classification of digital artifact integration in electric vehicle supply equipment (EVSE) and resulting possibilities for emobility service provider (EMSP) to develop business models. Additionally, the results strongly support the assumption that EMSP value creation, capturing and business model sustainability are highly reliant on the grade of digitalization within the business model. The paper provides background and deeper insights into digitization and digitalization in the field of emobility. Furthermore, it shows the applicability of the "Layered Modular Architecture" (LMA) in business modeling as an instrument for the identification of digital technology enhanced value propositions. Finally, LMA and Service-oriented Architecture (SOA)-concept are proposed to enhance business modeling in digitally transforming ecosystems.
\end{abstract}

Keywords: Digitization, Digital Transformation, Digitalization, Emobility, Business Model, Business Model Generation, Layered Modular Architecture

\section{$1 \quad$ Introduction}

Following the ongoing discussion on issues and potentials of digital transformation (DT), one has to conclude that digitalization is dramatically changing market transactions and jeopardizing existing business models (Hamidian and Kraijo, 2013; Hungerland et al., 2015). Leveraging the power of digitalization business models have to be innovated quickly and flexibly to survive and compete in the long term (Carayannis et al., 2014; Kagermann, 2015; Kane et al., 2015). Therefore, companies necessarily have to decide whether or not they want to be able to use information technology as an enabler and initiator within the development and transformation of existing and new businesses (Lusch and Nambisian, 2015). Not surprisingly, information systems science ranks research on business models and the impact of information and communication technology (ICT) on business models as a priority task. This task includes questions on ICT's transformative nature, the following impact on industrialization as well as new product and service models. Furthermore, IT support for developing and managing business models is addressed by means of substantiation of conceptual models, graphical representations and the design of software tools for supporting business model development (Veit et al., 2014). Out of managerial perspective research should answer 
the question how to identify digitization opportunities, risks and costs. Furthermore, the leverage of digitalization opportunities with regard to customer value propositions, remodeling business operations and enlarging business model scope and scale by identifying new customer channels and entering new markets. Answers can only be found by respecting the distinct nature of digitalization which is a sound basis for generativity as well as evoking high complexity in product, services and network partnerships. The ongoing emobility market development, which shows an increasing electric vehicle (EV) market coverage, is an excellent field of investigation for studying the generative potential of digitization and DT. Within a kind of greenfield new technological solutions with a high proportion of digitalized artifacts are introduced into an ecosystem where market participants from different origins, like the automotive, energy, transport and ICT industries, try to stake out their claim. Furthermore, complex digital issues in introducing new technology in "smart energy and transport markets" have to be overcome across industries' borders. Incumbents like the big car manufacturers are under pressure by market entrants that see cars as digital technology platforms and have digital technology at their core (Johansson and Deniz, 2014). Although emobility is currently a market niche, it is already obviously influencing the existing means of transport and underlying business models. Emobility market development shows new technical and digital solutions, creating new business partnerships and encouraging the discussion of existing mobility habits and associated business models. In addition, the convergence of the trend of digitalization, the offer of hybrid products (e.g., product service systems) as well as the role of network partnerships can justifiably be examined in this field of business (Fazel, 2014; Westphal et al., 2013).

As a first research outcome, this paper presents a generic classification of digital artifact integration in electric vehicle supply equipment (EVSE) and resulting possibilities for emobility service provider (EMSP) to develop business models. Furthermore, the study recommends utilization of the LMA for identification of digital technology enhanced business services. Additionally, the results strongly support the assumption that EMSP value creation, capturing and business model sustainability are highly reliant on the grade of digitalization within the business model. Finally, LMA and Service-oriented Architecture (SOA)-concept are proposed to enhance business model generation in digitally transforming ecosystems.

\section{Methods}

This research is based on design science (Hevner et al., 2004) and the design science research methodology (Peffers et al., 2007). A case study was conducted in autumn 2015 including a set of workshops. These were focused on investigating new business models for emobility products and services deployment based on EVSE and digitalization opportunities. In a first step, the deployment of EVSE at the industry-partner side was analyzed from early 2009 up to mid-2015 utilizing an adoption of the business model canvas (BMC) method (Osterwalder and Pigneur, 2010). The used adoption of BMC was focused on an elaboration of general services and infrastructure (physical, personnel, digital) relations as well as the related value proposition evolution over time. 
This was meant to be the starting point for future business model development as an EMSP. Reflecting the emobility market situation up to 2015, emobility service provider EMSP business is defined as a combination of charging-services operators' (CSO) and charging-services providers' (CSP) business. An EMSP thereby is a company running its own EVSE network and providing charging and information services for EVs regardless of whether they provide these services within their own or in foreign EVSE networks. By delivering these services, they create value for EV B2C and B2B users and in value chains through $\mathrm{B} 2 \mathrm{~B} 2 \mathrm{C}$ network business.

\section{$3 \quad$ State of the art}

The theoretical basis is enabled by an extensive review of the literature on digital artifacts, digital technology and digitalization. This supports the conceptual arguments and addresses the objective to derive insights into "digital nature" and their influence on business model generation. Therefore, as an important precondition, the state of the art regarding the nature of digital artifacts and digital technology has been analyzed. Furthermore, the literature on DT is evaluated to work out relations, impacts and opportunities for business models and business model generation. A general definition of a business model and a simple but effective classification model will be the conceptual bases for evaluation of digital technology's impact on business model opportunities within the emobility market development. In this section, the distinct characteristics of digital artifacts, the LMA of digital technology, the core design principles of digital technology as well as a definition for digital infrastructures will be introduced. This will be the basis for the definition of "digitalization" and help to back the understanding of digitalization of business models by providing an understanding and facilitating possibilities through form-giving structures of digitized physical products and services.

\subsection{Digital Artifacts and Digital Nature}

In the context of studying digital artifacts and digital technology, it is important to distinguish them from physical artifacts. With their theory on the nature and identity of technological objects, Faulkner and Runde (2013) presented a well-proven sound basis for identifying digital artifacts, their distinct attributes and design principles. They argue that objects are beside others, such as events and properties, basic kinds of entities. Regarding them as "structured continuants," they see objects as structured and composed of distinct elements. Technological objects are seen as a subset of objects that is specified by the function assigned to it by members of the human community. Technological objects can be separated into two categories, material and nonmaterial technological objects. The first possesses a physical mode of being, like office chairs and flipcharts, which have properties of location, mass, shape and volume. Nonmaterial technological objects have a nonphysical mode of being and thus are "aspatial." Nonmaterial, nonhuman technological objects are called syntactic entities and are composed of symbols that are formed by syntactic and semantic rules of the language in which they are couched. Examples of syntactic entities are research articles, product 
designs and bitstrings, such as computer files. In sum, Faulkner and Runde (2013) present three criteria for nonmaterial technological objecthood: continuants combined with structure, an agentive function imposed by human communities and a nonphysical mode of being.

An important implication of nonmaterial technological objects is that they may be distinct from material and other nonmaterial "bearers". For instance, bitstrings as a collection of $1 \mathrm{~s}$ and $0 \mathrm{~s}$ as such have no spatial attributes and rely on material technological objects, like computers or other nonmaterial objects, like operating systems, to be usable. However, they possess a particular technical identity like material objects. Technical identity thereby depends on the community in which it is "used and/or appropriately referenced if (1) it has assigned to it the function associated with that technical identity, and (2) its structure is such that it is generally able to perform that function" (Faulkner and Runde, 2013).

Kallinikos et al. (2013) introduce four significant attributes of these technological nonmaterial objects that they describe as "digital artifacts qua objects". These attributes describe the specific nature of digital objects or what we call the "digital nature". Examining the ambivalent ontology of digital artifacts, Kallinikos et al. give a broad overview of the existing literature on the ontology and properties of digital artifacts within IS research, concluding that "digital artifacts are intentionally incomplete and perpetually in the making" and "[...] they lack the plenitude and stability afforded by traditional items and devices" (Kallinikos et al., 2013).

Kallinikos et al. elaborate through their studies that digital artifacts can be distinguished from physical objects by their editability, interactivity, reprogrammability/ openness and distributiveness. The first three attributes concern the operations by which digital objects are put together (editability, interactivity, reprogrammability) and the last two the ecology of relations within which these operations are embedded (openness, distributiveness).

Editability thereby concerns the possibility to change a digital object constantly by reorganizing the constituent elements, by deleting or adding new elements or by modifying individual elements of the object. Hereby, the logical structure that governs the object and the mechanisms of information production and processing are not interfered with.

Digital artifacts are interactive in the sense of offering alternative possibilities of a contingent nature to activate their embedded functions or to discover the encapsulated information items. Interaction does not need to invoke change or modification of the object. This is facilitated by the "responsive and loosely bundled nature of the items that make up digital objects" (Kallinikos et al., 2013).

Openness and reprogrammability of digital artifacts describe the accessibility and modifiability by other digital objects that are not the ones governing their own behavior. This means that the logical structure of digital artifacts can be modified by other objects than the ones that govern and manage the mechanisms of information production and processing. Thereby, openness is closely tied to the interoperable character of digital artifacts.

As the result of openness and interoperability, digital artifacts are hardly ever contained within a single source or institution. Thus, they are classified as distributive in the sense 
that they are transient assemblies of functions, information items or components disseminated over digital ecosystems. Insofar as they are not bonded to an obvious entity and in being distributed the existence of various combinations of digital objects of the same kind is possible. By this they are borderless, fluid and crucially transfigurable (Kallinikos et al., 2013).

Kallinikos et al. further argue that digital artifacts "are further supported by the modularity and granularity of the ecosystems in which digital objects are embedded". In this context, digital artifacts are from Kallinikos et al.'s point of view associated with the concept of modularity in means of objects being relatively independently organized in blocks that constitute a system by "a wider yet loosely coupled network of functional relationships". These blocks are mediated through interfaces that can serve a broad spectrum of functions. The granularity of digital objects refers to the ingredients from which blocks are made and describes "the minute size and resilience of the elementary units or items by which a digital object is constituted" (Kallinikos et al., 2013).

\subsection{Digitization, Digital Technology and Layered Modular Architecture}

Based on this theory, we divide digital technology into digitized and digital artifacts. The second one stands for nonmaterial, nonhuman technological objects that fulfill all mentioned characteristics of nonmaterial technological objecthood. They result from "digitization" in the narrow sense, i.e., ,the encoding of analog information into digital format" (Yoo et al., 2010). Nonetheless, the combination of nonmaterial and material technological objects in the sense of e.g., an iphone application used on an iphone is a digital technology insofar as nonmaterial objects can be embedded into material technological objects. We call the technical process of embedding digital artifacts into material technological objects "digitization" in the broader sense. The results are called digitized or sometimes also referred as digitalized artifacts (Yoo et al., 2010). Consequently, digitized artifacts can be defined as the assemblages of digital and physical artifacts that are recognized as an end product to meet customer needs. Examples of digitized artifacts are everyday consumer products like mobiles and ebooks, but also a full range of industrial equipment, textile or car production robots.

As mentioned, digital technology will be further on understood as both digital and digitized artifact, which is seen as a structured and organized arrangement of material and nonmaterial technological objects consisting of computing, communication, interaction and information technologies (Bharadwaj et al., 2013). Furthermore, digital technology can be used as an enabling medium for designing and providing digital services offerings (Chowdhury, 2015).

It should be emphasized that according to Yoo et al. (2010) the incorporation of digital objects causes physical objects to adopt the characteristics of digital artifacts (Yoo et al., 2010), whereby these digitized objects are characterized by distinct trajectories of material and digital artifacts, meaning that the entity no longer follows one unified line of development. Insofar understanding digital, nondigital systems as well as the management of decoupled systems increases the complexity of the development and maintenance of business models within digitally transforming ecosystems (Bharadwaj et al., 201). 


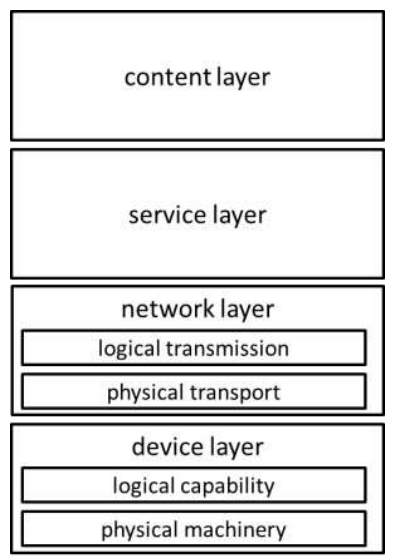

Fig. 1. Layered Modular Architecture (Source: Yoo et al., 2010)

Yoo et al. 2010 pointed out that with digitization a new LMA of digital technology emerged. This can be taken as a key enabler for digitization of technological objects and perfectly describes digital nature's configuration. LMA facilitates the separation of material and nonmaterial entities. It maintains an interoperability among the components by a hierarchical dependence between the layers (see Figure 1).

The LMA is designed by four loosely connected but interdependent layers: device, network, service and content. The device layer contains two kinds of technological objects. First, physical hardware units like computer hardware. Second, nonmaterial objects like operating systems providing control and maintenance of the physical machine functionality as well as connecting interfaces to the network layer. Similar to the device layer, the network layer consists of material as well as nonmaterial technological objects, providing a sublayer for physical transport like cables and radio spectrum as well as a sublayer for logical transmission with nonmaterial objects like network standards. The service layer enables direct interaction with users through application programs featuring functionality, like creating or consuming content. The highest layer comprises data like text, sounds or images as well as metadata and directory information about e.g., content's origin and ownership (Yoo et al., 2010). Following Yoo et al., predigital technology is featured by tightly coupled entities (such as books, analog telephone), or as in the case of purely physical or mechanical products (such as mechanical timers, powerlines, sockets) layers do not even exist. Digital technology facilitates through the separation of the four layers a free and individual design in between the different layer levels (Nylén, 2015). Digital technology is delivered intentionally incomplete with temporary bindings across the four layers. It is thereby following the procrastination principle, holding that a digital artifact "should not be designed to do anything that can be taken care of by its users" (Zittrain, 2008).

The open and dynamic breeding ground of digital technology, their catalyzing LMA, the fluid character of digital content and a rapid diffusion through the internet triggers unprecedented opportunities of generativity (Kallinikos et al., 2013; Zittrain, 2006). 
Generativity here refers to the "overall capacity of a technology to produce unprompted change driven by large, varied, and uncoordinated audiences" (Zittrain, 2006), which creates abundant opportunities for innovating products, services (Boland et al., 2007; Tilson et al., 2010; Yoo et al., 2010; Zittrain, 2006) and business models carrying out these innovations and themselves being influenced by "digital nature".

\subsection{Digitalization and Digital Innovation}

After having emphasized the distinct characteristics of digital artifacts, digitization and thereby the nature of digital technology as well as the generativity that is created by digital technology, there is a solid conceptual basis for understanding the impact and challenges for an industry facing digitalization. This phenomenon has recently been intensively discussed in applied managerial literature and science but surprisingly enough a commonly accepted or clear definition and understanding are still missing (Bounfour, 2016; Hanelt et al., 2015). Besides being mistakenly used as a synonym for digitization-which is, as already shown, a technical process of embedding digital technology into technological objects or the encoding of analog information into digital format-it is often discoursed in context to DT and digital innovation without clarifying the precise relationship between the notions.

Applied managerial literature tries simply to describe DT as "the use of new digital technologies (social media, mobile, analytics or embedded devices) to enable major business improvements (such as enhancing customer experience, streamlining operations or creating new business models)" (Fitzgerald et al., 2013).For sure, this definition can be seen as a very operational and holistic target identification.

More precisely, Tilson et al. (2010) characterize digitalization as "a sociotechnical process of applying digitized techniques to broader social and institutional contexts that render digital technologies infrastructural" (Tilson et al., 2010, p. 749). Consistently, Yoo et al. (2010) point out that by digitalization is meant "the transformation of sociotechnical structures that were previously mediated by non-digital artifacts or relationships into ones that are mediated by digitized artifacts and relationships. Digitalization goes beyond a mere technical process of encoding diverse types of ana$\log$ information in digital format (i.e., "digitization") and involves organizing new sociotechnical structures with digitized artifacts as well as the changes in artifacts themselves" (Yoo et al., 2010). Hence, the notion of digitalization includes the transformational digital nature as "a marked change in form, nature, or appearance" affecting individuals, firms, economies and societies (Lucas et al., 2013; Yoo et al., 2010) in part or as a whole by transformation of individual habits, organizational as well as operational structures through digital technology, including digital artifacts themselves. This can be characterized by a significant change in nature and focus of the business activities needed to acquire new capabilities or markets, and fundamental changes in tasks to leverage competitive advantages (Bounfour, 2016; Lucas et al., 2013).

Following this view, digitalization and DT can be understood synonymously. Hereby, it should be stressed, that digitization and digital technology provide the basis for digitalization and resulting opportunities for improvements of ecosystems' viability. These 
chances must be transferred into the context of ecosystems (i.e., systems of actors, technology, institutions, information, etc.) to capture value from digitization. Furthermore, the differentiation between digitization and digitalization is underlined by highlighting the sociotechnical perspective, the processual character and the impact on social entities (consumers and producers) and institutions (organizations and markets). In addition, a thorough understanding of digitalization's influence on processes, organizational forms, relationships, user's product or service experience, market coverage, customers and the overall disruptive impact of digitalization is covered (Lucas et al., 2013). Surely, conjured up by the distinct nature of digital artifacts, digitalization bears generativity and thereby unpredictable combinations of products, services, ways of operating businesses as well as business models carrying out these combinations into a market, creating a good seed ground for innovation (Bharadwaj et al., 2013; Henfridsson et al., 2014; Yoo et al., 2010; Yoo et al., 2012).

After having clarified the notion DT, digital innovation and the distinct relation between both notions will be elaborated. Innovation is "a new idea, device, or method," as well as "the act or process of introducing new ideas, devices, or methods" (MeriamWebster dictionary). Innovation of a new idea, device or method enabled by digital technologies is covered by the notion digital innovation. Further digital innovation includes the process of introduction of just these (Yoo et al., 2012).

However, we see an innovational character is a sufficient, but not necessary, condition to digitalization. This means that, from the perspective of the sociotechnical microsystem, every DT is conjunct with a kind of novelty due to introduction of new technological artifacts, changing value propositions, operational processes or business model architecture. Nevertheless, an innovation has to cover novelty characteristics to the macro level. DT thereby is not forced to cover the characteristics of innovation. DT can also be performed by a sociotechnical process of introducing well-known digital technology or digitized processes into new fields of application.

\subsection{Business Model Concept}

With the dot.com era came a discussion about and on the concept of business models in science and applied science literature popular. Management scholars tried to find out how business works and how value is created, especially because billions of dollars had been spent on "business models" that later turned out to fail (DaSilva et al., 2014). Since then, researchers and practitioners have made a considerable number of attempts to define, describe and operationalize the business model concept (Fielt, 2014; Petrikana et al., 2015). Nevertheless, there does not exist a commonly accepted definition of business models and their conceptual components. Furthermore, the concept boundaries of application differ according to context and conditions (Fielt, 2014).

Following Fielt's comprehensive study on business model definitions and concept elements, a business model can be defined out of a generic and holistic point of view in the way that "[it] describes the value logic of an organization in terms of how it creates and captures customer value and can be concisely represented by an interrelated set of elements that address the customer, value proposition, organizational architecture and economics dimensions" (Fielt, 2014). This definition follows major and well-accepted 
focal firms' oriented research and practitioner streams (e.g., Chesbrough, 2007; Johnson, 2010; Osterwalder and Pigneur, 2010) explicitly focusing on customer value creation. It understands value delivery included in the value creation process, because "[the] separation of creating value and delivering value [is seen] as a supply-side perspective focusing on producers adding value. Customer (use) value cannot be created without involving the user and considering the use context" (Fielt, 2014).

As an instrument for strategic analysis and planning, business models are used to explain value chains or lately even more value networks from the perspective of a focal firm in an aggregated form and describe how activities are combined to execute a firm's strategy (Petrinka et al., 2014). Understanding a business model in this form, they can be seen as "reflections of the realized strategy" (Casadesus-Masanell and Ricart, 2010) and as what a company is actually delivering at a certain time. Therefore, business strategy and business models are closely interlinked as business models are part of the strategy work and execution (Demil and Lecocq, 2010). It is commonly accepted that a firm not only can use the business model concept for reasoning about different business models. Even more different business models can be executed in coexistence within a company's strategic portfolio (Trkman et al., 2015). Thereby, a "business model as a model" is a relevant and useful "manipulable instrument" to help scholars and managers in reflecting what a firm does or could do to create and capture value. Furthermore, it can change its existing models to fit with changes in technology or market conditions (Baden-Fuller and Haeflinger, 2013).

\section{$4 \quad$ Results}

Taking the described role of business models into account, an in-depth analysis of digital technology capabilities and their relation to business model capacities was conducted. As mentioned, the analysis was performed as an over-time evaluation of business development at an Austrian first mover EMSP. It was part of the business model analysis and development process that was meant to guide the company's emobility strategy 2020.

In a kind of bottom-up approach, EVSE hard- and software development cycle was structurally captured in the LMA and mapped to the accessible functions within the "EVSE service layer". Onwards it was analyzed to identify physical as well as ICTrelated services using a business model as a model to reflect business value creation and capture opportunities and evolutionary prospects through digitized EVSE technology (see Figure 2).

\subsection{Digitizing EV Supply Equipment}

The starting point of the investigation was the analysis of an EVSE. As a connection point between the EV, energy grid and transport infrastructure, an EVSE is part of the infrastructure to supply a vehicle's battery with energy. It is used to connect EVs to the energy grid and transfer energy from the grid into the car or back. An EVSE is physically connected to parking lots and an essential part of EV transport systems. 
Based on an "EV charging use case" for charging EVs on public and semi-public ground, identified functions of the EVSE were mapped in the "EVSE service layer". Existing or generated information assets were afterwards mapped into the "EVSE content layer" to discover content-based service development opportunities.

"Energy charging" is the basic physical service that is promoted by an EVSE. To support charging with higher supply power, a rudimentary ICT has to be embedded into the EVSE support "type 2 and Combined Charging Systems (CCS) charging". From historical reflection, it was deduced that a "geoinformation service" as a basic ICT service was established to inform EV drivers about charging possibilities' location and capabilities. Media disruption of the service was performed manually by transferring geoinformation and technical configuration of the EVSE into central registers on websites (see lemnet.org). Later on, in higher stages of integration, this service was part of EVSE management systems. Adding remote ICT management capabilities and embedding communication facilities (Global System for Mobile Communications (GSM) and network protocols) into EVSE (see types 4 and 5) has to be noted as an important step in digitization of EVSE. Interconnection of EVSE bridges the layers of LMA and enables the development of various content-related ICT services as well as ICT-enriched physical services. The automated transfer of geoinformation (e.g., in the first stage as Excel-extractions) as well as "digital authorization services" of customers are a kind of ICT service to ease use of infrastructure. Authorizations for charging are necessary to ensure legal safety issues as well as economic basics. Without ICT, these had to be performed, e.g., by hardware keys or coins. ICT allows in the first step (EVSE type 3) the handling of, e.g., RFID-access cards later on (EVSE types 4 and 5), purely digital authorization via SMS gateways or other internet-based services. This allows a variety of digital "payment services" e.g., usage-based pricing, prepaid or pay-as-you-go models. Digitizing EVSE with interconnection to a central system further enables physical "infrastructure maintenance services" optimization by transferring use or failure notice to the system. Based on this, information maintenance workflows can be performed along with real-time failure or pricing information transfer to customers' devices as well as "EVSE reservation services". Embedding "webservice interaction" capabilities unleashes alongside easy integration of state-of-the-art internal management systems (e.g., demand side and energy management, customer interaction centers, workflow management systems) the possibility seamlessly to interact with third-party systems and thereby a controlled management of EVSE by business partners.

Not surprisingly, one can find out by analyzing the content layer that data utilization and information retrieving is highly dependent on the underlying layers. In particular, information assets are lost when EVSE that is not interconnected is used, whereby use of an insular EMSP management with no online connection at least bears possibilities of utilization analysis and usage-based pricing on a subscription base. Through loosely coupling the layer's accessible content that is stored once online, the real potential of digitization can be fully leveraged. E.g., geodata in combination with utilization and availability can be used by third-party services for new value creation in a smart grids context or route planning services within the EV. At the least, it has to be determined that the data are available, compatible and valid. Figure 2 illustrates with five types of 
EVSE and interacting ICT components that influence the loosely coupled LMA layers by digitization of EVSE on service capacities and information utilization.

Thereby, utilization of LMA and acknowledgment of the digital nature in the sense of editability, interactivity, openness and distributiveness enable recombination of EVSE and systems as well as interactions with third-party services. By this, innovation can evolve very fast, like adding state-of-the-art webservice-based payment methods to an EVSE without influencing or even touching first- and second-layer technology. From an industry partner's perspective, this has a great influence on customer friendliness and economic efficiency by having no need to work on infrastructure in the field.

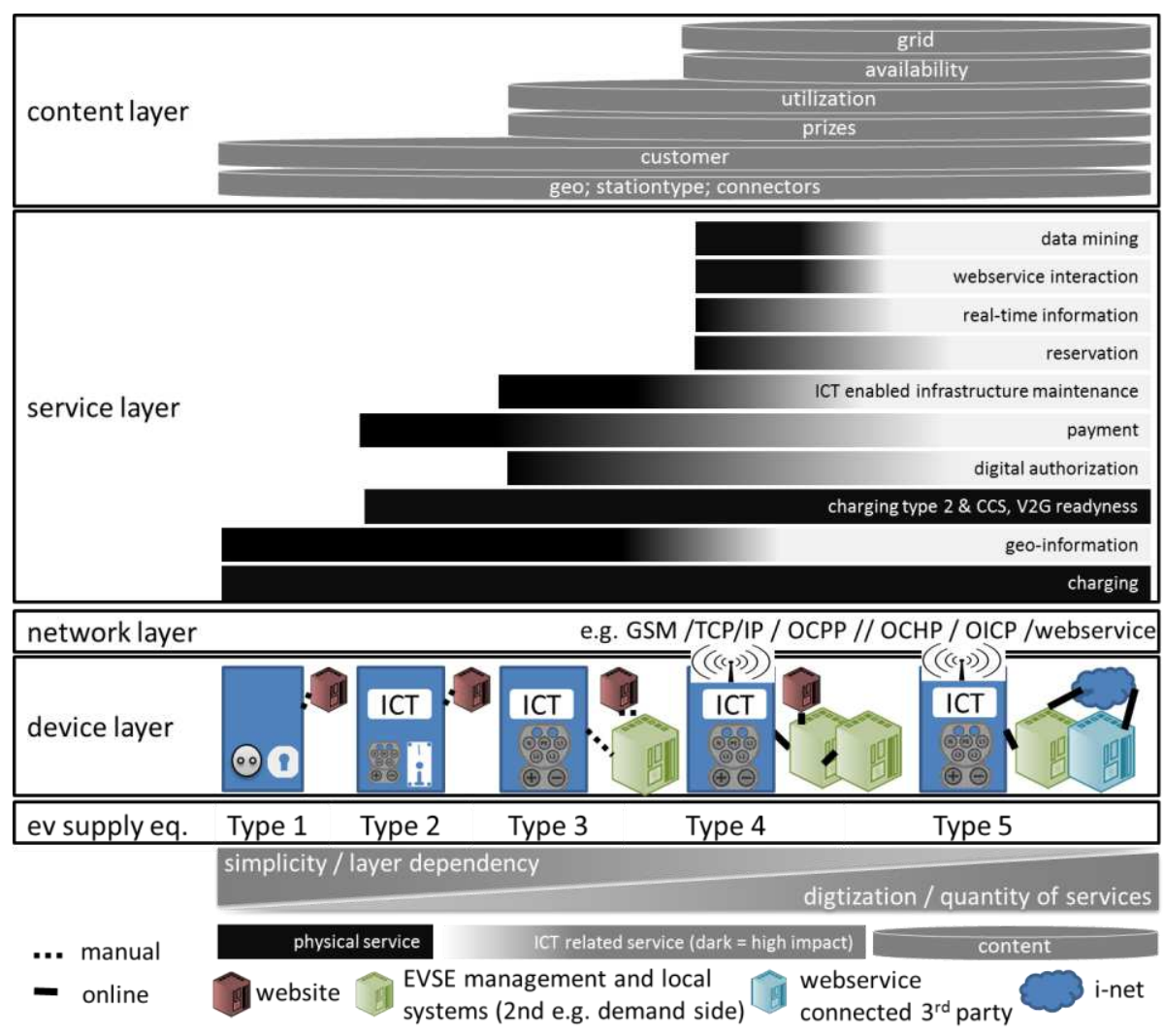

Fig. 2. Layered Modular Architecture Electric Vehicle Supply Equipment (Source: own diagram)

In summary, it can be noted that by embedding digital technology regarding layer independence and using open standards, the variety of services performed or enabled through EVSE rises exponentially. Open standards bridging the first two layers enable an individual design in between the layers and thereby a new product and service development in and with the upper layers (e.g., maintenance optimization, smart energy integration). 


\subsection{Digitalization of Emobility Service Provider Business Model}

Focusing on EMSP business, the elaboration of the described technology-based LMA "service layer" was the starting point for a technology-based approach describing generic business models. Following the assumed business model definition, the focused elements for modeling were value creation and value capture. Without conducting an in-detail business model development process, the identified "EVSE service layer" was transferred into value creation core business process services enabled by EVSE functionality. Categorized in material, ICT-related basic and comfort business services (including customer handling), they describe constituent characteristics of the value-creation process of EMSP firms. Thereby, digitization's influence on business model digitalization opportunities in value creation was elaborated and transferred in five generic EMSP business models. Furthermore, related value capture models, flexibility of revenue model change were applied, reflecting technological possibilities. Last but not least, business model scalability and scopability as well as capital expenditure (CAPEX) and operational expenditure (OPEX) were analyzed under the ceteris paribus clause in relation to ICT impact.

The key service to generate customer value in an EV charging use case is the "energy supply" service. To make this service available, physical value generation is needed in the sense of deployment and maintenance of EVSE facilities providing energy supply for EVs. Physical services within the field of "smart grid integration" e.g., grid stabilization, are allocated in comfort physical services with a high degree of ICT impact. Nonphysical values are purely digital information services (e.g., EVSE geoinformation). These services are in general attached to CSO business, which can further be expanded to create value within $\mathrm{B} 2 \mathrm{~B} 2 \mathrm{C}$ relations by providing $\mathrm{CSO}$ service for third parties (Madina et al., 2016). Within this application, EMSP is the supplier to other EMSP or Smart Energy Providers (SEP). SEP act within the smart energy business, optimizing demand and supply within energy networks. Physical services are, beside the basic services, comfort services e.g., active- or demand-side management by managing EV energy consumption (Giordano and Fulli, 2012). Furthermore, ICT-related services like "emobility marketplace connectivity" facilitate third-party customer authorization and media-disruption free data exchange for billing and settlement of transactions (Pfeiffer and Bach, 2012).

Following the general market development and the forerunning business activities of the evaluated industry partner in the beginning of 2009, five generic business models have been deduced (see Figure 3). These correlate in high degree with EVSE digitization.

\section{Simple Business Model "EVSE type 1 and 2".}

Early business models (models 1 and 2) were focused on value creation with physical services accompanied by very simple, not usage-based revenue models. Scalability and scopability of these models is low because the switching cost to guarantee better service quality or setting up new services is very high. Digital assets like geoinformation and usage-based prices cannot be leveraged. CAPEX is quite low, due to the very simple infrastructure and no or little investment in ICT necessity. OPEX for these business 
models is high in the sense of EVSE check-up and sanity-testing due to the cost of having personnel monitoring the infrastructure in the field. Even more, the reliability of EVSE is very low whereby customer satisfaction is low e.g., customers drive to EVSE that are out of order because no online information is available.

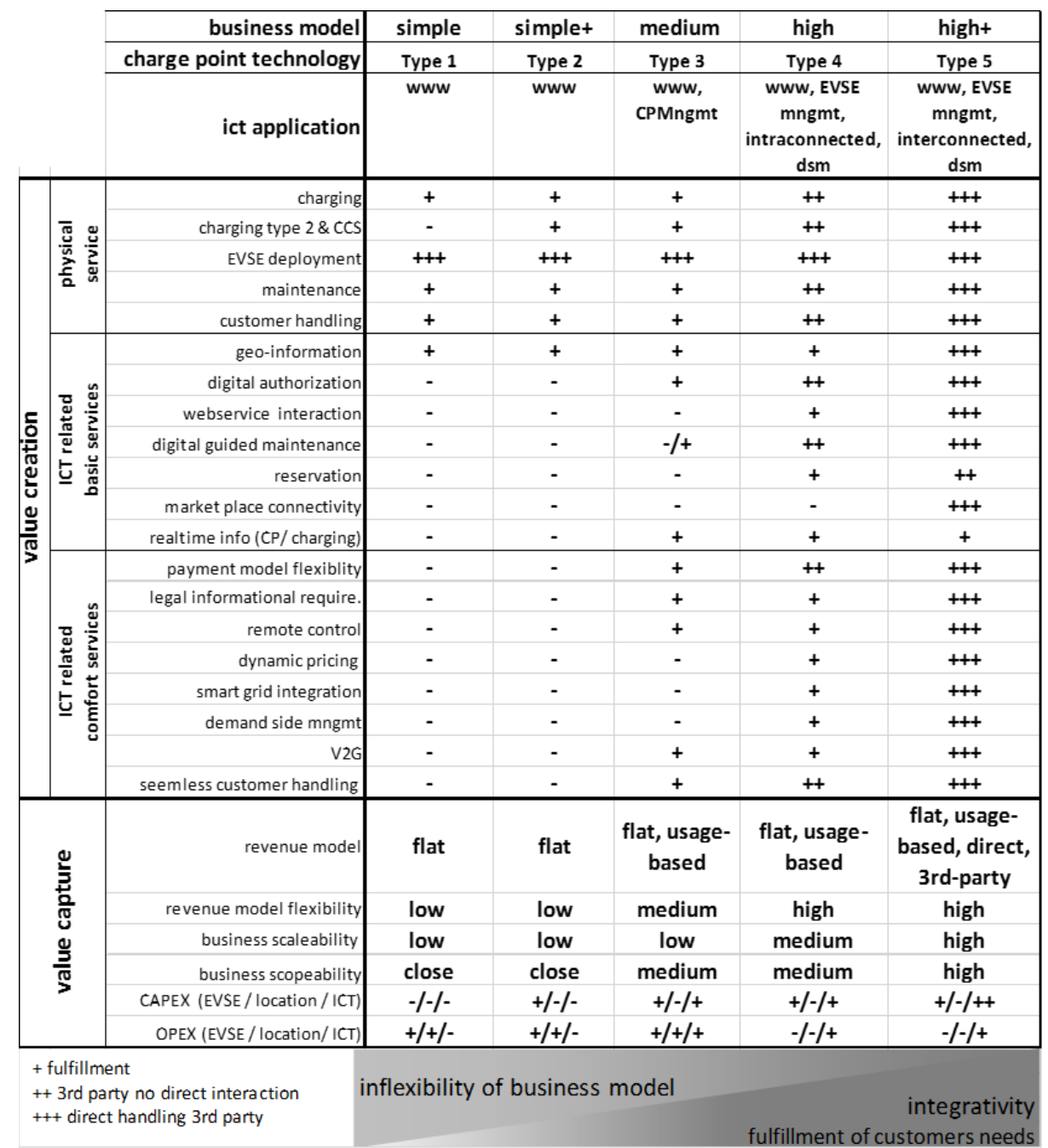

Fig. 3. Generic Emobility Service Provider Business Models (Source: own diagram)

\section{Medium Business Model "EVSE type 3".}

The cost of usage-oriented price models and optimization of authorization handling in business model 3 forced the embedding of EVSE type 3 technology. While this allowed more flexibility in the refinement of the revenue model, CAPEX and OPEX rose due to ICT integration without enabling further compensation through additional services 
or customer attraction. Quality of service optimization by integration of digitally guided maintenance on a basic level (e.g., using age of EVSE in combination with usage information) within the system were likely to be achieved.

\section{High Business Model "EVSE type 4".}

The next step in the development was models using type 4 EVSE technology, which enabled intra-connected EVSE and application communication. These types of business models offer on the one hand optimization of customer handling on physical as well as digital bases e.g., through integration into company workflows, direct user registration and online status information on the website. On the other hand, quality of service on EVSE sites could be optimized by real-time status information and automation of maintenance workflows. Arising communication costs could easily be recouped through active maintenance management. Nevertheless, these kinds of business models are limited by an insular setup, not realizing opportunities of generating value through ICT-based integration of partner services as well as being unable to seamlessly offer their services in other application fields (e.g., traffic management, smart grid integration). EVSE type 4-based business models have flexible revenue models, an optimized OPEX situation and are under conditions of state-of-the-art ICT architectures, e.g., webservice technologies, characterized by a medium scalability and the business scope can be expanded with medium effort. This in particular is because of having no need to change EVSE in the field that were already equipped with ICT-communication facilities.

High+ Business Model "EVSE type 5".

State-of-the-art business models facilitating EVSE type 5 technology can be classified as highly flexible in scaling business and broadening the scope of business activities in other fields and markets. Leveraging the possibilities of a digital nature, they achieve unprecedented opportunities for offering new ICT-based products and services by associating their physical and digital assets with their own or network partners' services. While being based on ICT-embedded EVSE they take advantage of LMA architecture, being able to combine any content with any service and device e.g., integrating proved ecommerce techniques into the emobility market. The key enabler is the interconnection of EVSE as devices with a modular EVSE management system supporting loosely coupled standardized interfaces to other systems. This local, decentralized intelligence can be combined with central management systems' capabilities to fulfill smart grid integration services, e.g., to manage charging of EVs' fluctuating infeed from renewable energy sources (Giordano and Fulli, 2012). Even more integration into traffic systems is required to fulfill local authority or car sharing companies' needs in managing parking areas and charging facilities (Beutel et al., 2104). Services like seamless digital customer handling, dynamic pricing, fulfillment of legal informational requirements or the integration of state-of-the-art direct payment possibilities lead to higher customer satisfaction, product differentiation and optimized OPEX. By integration of third-party processes in the value chain up- and downstream, highly efficient interaction with network partners as well as with B2B customers is guaranteed. Finally, even a B2B2C 
business in the sense of realization of purely CSO business is possible, reducing endcustomer handling obstacles and enabling core business-focused strategies while delivering a high quality and efficient CSO service. Overall, this EVSE type 5 empowers very flexible and different revenue flows from a multitude of resources and customers.

\section{Discussion}

This paper has examined the opportunities of digitized technology for business model development and business transformation. The basis was an in-depth analysis of the historical development of ICT-enhanced infrastructure in the emobility charging market based on an application of digital technology's LMA. Originating from the digitization of EVSE, five generic business model types were conducted and analyzed. In a first step, the LMA service layer's digital technology-based services were transferred into a business model description. Value creation as a core element was described by core business process service elements. Further on, value-capturing opportunities and business model evolution prospects were deduced based on the elaborated business process services. Value capturing was therefore categorized into a revenue model, business scope and scale, as well as OPEX and CAPEX of the business model.

The investigation showed that basic customer needs-charging services-can be fulfilled by any of the EVSE-based EMSP business model approaches. However-from the customers' perspective-the quality of service and value-added services (e.g., real-time geoinformation) as well as the flexibility of payment and contractual models rises by using digitized EVSE equipment. These effects are ceteris paribus accompanied by higher CAPEX for investment into ICT (EVSE and backend systems). Further, by implementing EVSE type 4 and higher technology, lower OPEX can be achieved through digitally optimized manual processes, e.g., by preventive maintenance or remote assistance.

From the industry partners' perspective, the higher investment in digital EVSE technology and ICT backend systems thereby can be significantly compensated by minimizing manual services processes in the field. In addition to the just mentioned values for customers' quality and flexibility perception and business models' cost structures, further benefits can be achieved. Digital technology-based service enhancement enables higher flexibility of the revenue model (e.g., usage-based tariffs, geoinformation services for third parties) as well as a higher scalability and scopability of the business model itself. As EMSP business models are operating in the emobility market, there are various opportunities for promoting value-added services in the transport and energy market. This underlines the assumption that the digital nature makes product and service boundaries become fluid (Yoo et al., 2010). In the current case, it descends as the digital offspring of EVSE type 5's digital nature. This type of "charging system" is creating unprecedented possibilities for product and service innovation e.g., by promoting services in the energy and transport system (e.g., information services and smartgrid services). The later stages of developing type 5 technology enable an enrichment of EMSP business models by promoting new services based on already existing technology in the field. Furthermore, it has to be stated that the digital nature obviously can 
make its generativity significantly stronger through implementation of open, accessible, interoperable and interconnected technology following the LMA architecture model bringing the layers' borders. To safeguard the business model's sustainability and create a future-proof setup, industry partners' experience suggests strongly that ICT should be embedded at least with state-of-the-art technology acknowledging the LMA. This means to force layer independence, which is not regarded within EVSE for types 1 to 3. In the current case, it is an interconnected infrastructure setup as in types 4 and 5 EVSE based on webservice technology. It has been experienced that it is highly costly and inhibits quick-to-market strategies with solid blocks of soft- and hardware. Even more practice has shown that dump EVSE as well as closed-shop infrastructure systems (up to EVSE type 3) lower business model development possibilities by forcing high changing cost at EVSE deployment sites accompanied by high complexity of managing the different trajectory paths of digital and physical technologies in the field.

\section{Conclusion and Outlook}

Overall this paper demonstrates the applicability of digital technology's LMA in the context of business model development. In the current case it was possible to deduct business models value creation and capturing elements based on technology choice. The generic set of EMSP business models can be taken as an impressive proof of digital technology's generative influence on business model's variety. This can be characterized by a high combinability of offerings creating crucially "transfigurable" business models. In line with Yoo et al. 2010 it has been shown that the digital transformation in the emobility market setup profoundly influences value creation and capturing options. Digital technology passes on its "digital nature" and business models apparently tend to take shape of borderless, fluid and crucially transfigurable entities. In digitally transforming ecosystems business relevant digital artifacts transmit their inherent appearance to business models. These take over the specific characteristics of editability, interactivity, openness and distributiveness evoking generativity and thereby unpredictable combinations of value creation and capturing.

More precisely, it should be stressed in this context that business models are more flexible and future-proof building on digital technology which follows the loosely coupled LMA. Business models utilizing this "digital abstraction layer" enable a mix-and-match of digitized resources (e.g., content, services and material technology) paving the way for generative value creation. This leads to business models transcending industry, product and service borders. Hereby, these business models are prepared to fulfill future customer's needs through evolutionary recombination of existing business model components (e.g., digital and non-digital resources, partnerships). Following this logic means to question established views on business model design and business strategy to cope with and proactively utilize changes in scale, scope, speed and sources of value through digitization (Bharadwaj et al., 2013; Lusch and Nambisan, 2015; Barret et al., 2015)

This study is exploratory in three senses. Being based on the expert knowledge and experiences of a pioneering company in the young field of emobility, it provides an 
overview on digital technology and business development from 2009 till 2015. Thereby, insights from digital technology's influence on business deployment over time are gained. This provides a fertile ground for deducing learning for future business generation in the emobility market at a highly digitized point of intersection between smart transport and energy markets.

Furthermore, it demonstrates the generative character of digital technology and the exploratory design of LMA utilized as a basis for an advanced business modeling in digitized market settings. Applying the LMA's "service layer" within businesses' value proposition design, unprecedented possibilities are generated by digital technology becoming visible. Thus, e.g., already identified customers' issues can be solved (e.g., "Is the EVSE I'm heading for available?," "I want to pay-as-I-go!") or customers' needs that they do not even know (e.g., "Energy price optimization by energy market optimized charging") can be addressed by digital technology-based services. Using EVSE type 5 technology, existing digital services from other fields of application can easily be involved to solve these issues, which brings time-to-market and cost-structure advantages (e.g., use of Google maps and integration of PayPal payment services). Moreover, other fields of application and customers can be addressed, expanding the scope and scale of EMSP business models by detection of EVSE-based business services.

Last but not least, the observations suggest gaps in existing business modeling approaches and underling theoretical interpretation schemes of economic exchange in the digital era. It indicates that business modeling within digitized market setups should facilitate LMA and a service architecture-based approach to identify profitable value creation and capturing opportunities. These are often rather characterized by "immaterial" than "material" values and a transcending value creation process. Following the structure of a LMA, the generative digital nature can be leveraged and transferred into business models carrying digital technology into reality. In accordance with the elaborated digital nature, we see flexibility, loose coupling of elements, granularity and modularity as key design principles for business models. Therefore, future directions of research may lead to the application of the "Service-Oriented Architecture" (SOA) concept into business modeling approaches to facilitate value identification through service-oriented business modeling.

Taking digital nature-here especially the LMA-and business model concept's service perspective into account, the SOA concept seems to deliver compatible components and methods for analyzing, developing and managing business models in digitally transforming ecosystems. The SOA concept is strictly based on the principles of modularity and granularity. These are fundamental elements of digital nature's generative matrix, enabling better maintenance and development of existing business models, identification of new offerings through flexible recombination of services as well as the exploration of business network partnership by using well-proven SOA methods. SOA's design principles of modularity, loose coupling and standards foster digital technology capabilities: reusability, distributiveness and interoperability (Luthria and Rabhi, 2015; Mueller et al., 2010).

Because of its exploratory character, the study was limited in several aspects by focusing on EVSE technology and analyzing EMSP business models. Thereby, simplifications regarding automotive and energy market integration were applied. For instance, 
the analysis was conducted reflecting the grid and EV as "black boxes" with interfaces to use EVSE as a physically connected point of grid and EV to deliver and acquire possible services and vice versa. Besides this digital technology, like battery management systems, smart grid management systems, navigation systems or mobile smartphone applications were assumed as ways to interact with the infrastructure but not being part of the investigation. Furthermore, customer's willingness to pay for quality of service and value-added services was not part of the investigation as well as strategic issues regarding customer accountability in B2B2C relationships were neglected. Last but not least, data security and privacy as well as regulatory requirements should be examined in further research.

\section{References}

1. Baden-Fuller, C. \& S. Haefliger: Business Models and Technological Innovation, Long Range Planning, 46(6): 419-426 (2013)

2. Barrett, M., Davidson, E., Prabhu, J., \& Vargo, S. L.: Service innovation in the digital age: key contributions and future directions. MIS quarterly, 39(1), 135-154. (2015)

3. Bharadwaj, A., El Sawy, O. A., Pavlou, P. A., \& Venkatraman, N.: Digital business strategy: toward a next generation of insights. Mis Quarterly, 37(2), 471-482. (2013)

4. Beutel, M. C., Gökay, S., Kluth, W., Krempels, K.-H., Samsel, C., \& Terwelp, C.: Product oriented integration of heterogeneous mobility services. In Intelligent Transportation Systems (ITSC), 2014 IEEE 17th International Conference on (pp. 1529-1534). IEEE (2014)

5. Boland Jr, R. J., Lyytinen, K., \& Yoo, Y.: Wakes of innovation in project networks: The case of digital 3-D representations in architecture, engineering, and construction. Organization Science, 18(4), 631-647 (2007)

6. Bounfour, A.: Digital Futures, Digital Transformation (2016)

7. Carayannis, E. G., Sindakis, S., \& Walter, C.: Business model innovation as lever of organizational sustainability. The Journal of Technology Transfer, 40(1), 85-104 (2014)

8. Casadesus-Masanell, R., \& Ricart, J. E.: From strategy to business models and onto tactics. Long range planning, 43(2), 195-215 (2010)

9. Chesbrough, H.: Business model innovation: it's not just about technology anymore. Strategy \& Leadership 35, 12-17 (2007)

10. Chowdhury, S.: Service Logic in Digitalized Product Platforms - A Study of Digital Service Innovation in the Vehicle Industry (2015)

11. DaSilva, C. M., \& Trkman, P.: Business model: what it is and what it is not. Long Range Planning, 47(6), 379-389 (2014)

12. Demil, B., \& Lecocq, X.: Business model evolution: in search of dynamic consistency. Long range planning, 43(2), 227-246 (2010)

13. Donada, C., \& Attias, D.: Food for thought: which organisation and ecosystem governance to boost radical innovation in the electromobility 2.0 industry? International Journal of Automotive Technology and Management, 15(2), 105-125 (2015)

14. Fazel, L.: Akzeptanz von Elektromobilität: Entwicklung und Validierung eines Modells unter Berücksichtigung der Nutzungsform des Carsharing. Springer-Verlag (2014)

15. Faulkner, P., \& Runde, J.: Technological objects, social positions, and the transformational model of social activity. Mis Quarterly, 37(3), 803-818 (2013)

16. Fielt, E.: Conceptualising business models: Definitions, frameworks and classifications. Journal of Business Models, 1(1) (2014) 
17. Fitzgerald, M., Kruschwitz, N., Bonnet, D., \& Welch, M.: Embracing digital technology: A new strategic imperative. MIT sloan management review, 55(2), 1 (2014)

18. Giordano, V., \& Fulli, G.: A business case for Smart Grid technologies: A systemic perspective. Energy Policy, 40, 252-259 (2012)

19. Hamidian, K., \& Kraijo, C.: DigITalisierung-Status quo. In Digitalisierung und Innovation (pp. 1-23). Springer Fachmedien Wiesbaden (2013)

20. Hanelt, A., Piccinini, E., Gregory, R. W., Hildebrandt, B., \& Kolbe, L. M.: Digital Transformation of Primarily Physical Industries-Exploring the Impact of Digital Trends on Business Models of Automobile Manufacturers (2015)

21. Henfridsson, O., Mathiassen, L., \& Svahn, F.: Managing technological change in the digital age: the role of architectural frames. Journal of Information Technology, 29(1), 27-43 (2014)

22. Hevner, R., et al. Design science in information systems research. MIS quarterly, 28. Jg., Nr. 1, S. 75-105 (2004)

23. Hungerland, F., Quitzau, J., Zuber, C., Ehrlich, L., Growitsch, C., Rische, M. C., ... \& Haß, H. J.: The digital economy (No. 21e). Strategy 2030-Wealth and Life in the Next Generation (2015)

24. Johansson, M., \& Deniz, S.: Ecosystem Changes in the Automotive Industry: Electric Vehicles and the Increased Importance of Network Business Models. European Electric Vehicle Congress Brussels, Belgium, third-5th December 2014 (2014)

25. Johnson, M. W.: Seizing the white space: business model innovation for growth and renewal. Harvard Business Press (2010)

26. Kallinikos, J., Aaltonen, A., \& Marton, A.: The ambivalent ontology of digital artifacts. Mis Quarterly, 37(2), 357-370 (2013)

27. Kane, G. C., Palmer, D., Phillips, A. N., Kiron, D., \& Buckley, N.: Strategy, not Technology, Drives Digital Transformation (2015)

28. Kagermann, H.: Change Through Digitization-Value Creation in the Age of Industry 4.0. In Management of Permanent Change (pp. 23-45). Springer Fachmedien Wiesbaden (2015)

29. Lucas, H. C., Agarwal, R., Clemons, E. K., El Sawy, O. A., \& Weber, B.: Impactful research on transformational information technology: An opportunity to inform new audiences. Mis Quarterly, 37(2), 371-382 (2013)

30. Luthria, H., \& Rabhi, F. A.: Service-Oriented Architecture as a Driver of Dynamic Capabilities for Achieving Organizational Agility. In The Handbook of Service Innovation (pp. 281296). Springer London. (2015)

31. Lusch, R. F., \& Nambisan, S.: Service Innovation: A Service-Dominant Logic Perspective. Mis Quarterly, 39(1), 155-175 (2015)

32. Nylén, D.: Digital innovation and changing identities: investigating organizational implications of digitalization (2015)

33. Newcomer, E., \& Lomow, G.: Understanding SOA with Web services. Addison-Wesley (2005)

34. Madina, C., Zamora, I., \& Zabala, E.: Methodology for assessing electric vehicle charging infrastructure business models. Energy Policy, 89, 284-293 (2016)

35. Matt, C., Hess, T., \& Benlian, A.: Digital Transformation Strategies. Business \& Information Systems Engineering, 57(5), 339-343 (2015)

36. Mueller, B., Viering, G., Legner, C., \& Riempp, G.: Understanding the economic potential of service-oriented architecture. Journal of Management Information Systems, 26(4), 145-180. (2010)

37. Osterwalder, A., \& Pigneur, Y.: Business Model Generation: A Handbook for Visionaries, Game Changers, and Challengers. John Wiley \& Sons (2010) 
38. Peffers, K., Tuunanen, T., Rothenberger, M. A., \& Chatterjee, S.: A design science research methodology for information systems research. Journal of management information systems, 24(3), 45-77 (2007)

39. Petrikina, J., Drews, P., Schirmer, I., \& Zimmermann, K.: Integrating business models and enterprise architecture. In Enterprise Distributed Object Computing Conference Workshops and Demonstrations (EDOCW), 2014 IEEE 18th International (pp. 47-56). IEEE (2014)

40. Pfeiffer, A., \& Bach, M.: An E-Clearinghouse for Energy and Infrastructure Services in EMobility. In Operations Research Proceedings 2012 (pp. 303-308). Springer International Publishing (2012)

41. Rammler, S.: Schubumkehr-Die Zukunft der Mobilität. S. Fischer Verlag (2014)

42. Tilson, D., Lyytinen, K., \& Sørensen, C.: Research commentary-digital infrastructures: the missing IS research agenda. Information systems research, 21(4), 748-759 (2010)

43. Trkman, P., Budler, M., \& Groznik, A.: A business model approach to supply chain management. Supply Chain Management: An International Journal, 20(6), 587-602 (2015)

44. Westphal, J. N., \& K.-D. Thoben: „Steigerung der Attraktivität von Elektroautomobilendurch neue Produkt-Service-Kombinationen“, Industrie Management, 29, 19-24 (2013)

45. Veit, D., Clemons, E., Benlian, A., Buxmann, P., Hess, T., Kundisch, D., \& Spann, M. Business models. Business \& Information Systems Engineering, 6(1), 45-53 (2014)

46. Yoo, Y., Henfridsson, O., \& Lyytinen, K.: Research commentary-The new organizing logic of digital innovation: An agenda for information systems research. Information Systems Research, 21(4), 724-735 (2010)

47. Yoo, Y., Boland Jr, R. J., Lyytinen, K., \& Majchrzak, A.: Organizing for innovation in the digitized world. Organization Science, 23(5), 1398-1408 (2012)

48. Zittrain, J. L.: The generative internet. Harvard Law Review, 1974-2040 (2006)

49. Zittrain, J.: The future of the internet-and how to stop it. Yale University Press (2008) 